\title{
Properties of Convergent Thalamocortical and Intracortical Synaptic Potentials in Single Neurons of Neocortex
}

\author{
Ziv Gil and Yael Amitai \\ Department of Physiology, Zlotowski Center for Neuroscience, Faculty of Health Sciences, Ben-Gurion University, Beer- \\ Sheva, Israel 84105
}

We explored differences in the properties of convergent afferent inputs to single neurons in the barrel area of the neocortex. Thalamocortical slices were prepared from mature mice. Recordings were made from neurons in layer $\mathrm{V}$, and either thalamocortical afferents or horizontal intracortical axons were stimulated. Monosynaptic EPSPs from both sources had latencies shorter than $1.8 \mathrm{msec}$ and low shape variance. Disynaptic thalamocortical IPSPs had latencies longer than $1.8 \mathrm{msec}$. All neuronal types, as defined by intrinsic firing patterns, received both thalamocortical and intracortical monosynaptic input. The shape parameters (rate of rise and half-width) of monosynaptic EPSPs from the two inputs did not differ significantly. The rate of rise of EPSPs varied considerably across cells, but the rates of rise of thalamocortical and intracortical EPSPs onto single cells were strongly correlated.

The relative thresholds for activation of synaptic excitation and inhibition were strikingly different between the two tracts: thalamocortical stimulation induced $\mathrm{GABA}_{A}$-dependent IPSPS at stimulus intensities equal to or less than those required for evoking EPSPs in $35 \%$ (24 of 68 ) of the cells. In contrast, the threshold response to intracortical stimulation was always an EPSP, and only stronger stimuli could generate di- or polysynaptic IPSPs.

We suggest that postsynaptic factors may tend to equalize the waveforms of EPSPs from thalamocortical and intracortical synapses onto single neurons. A major difference between the two convergent tracts is that the thalamocortical pathway much more effectively activates feedforward inhibitory circuits than does the horizontal intracortical pathway.

Key words: barrel cortex; thalamocortical synapses; intracortical synapses; local cortical circuit; feedforward inhibition; EPSPs; slices
Neurons in the neocortex receive convergent synaptic inputs from ascending pathways via various thalamic nuclei and from pathways that originate in neurons of the same area and other remote cortical regions. Understanding how the information conveyed by the various afferent systems is combined and processed in a single cortical area is of major importance to understanding cortical organization and function.

Two contradictory views of cortical organization have emerged from anatomical studies examining the cellular elements that are postsynaptic to identified inputs. One view suggests that wiring is made randomly (Braitenberg and Schüz, 1991), based on findings that axonal pathways synapse onto every neuron within their target region. On the other hand, studies by White and colleagues show that there is wide variation in the number and proportion of thalamic terminals synapsing on different types of cells, suggesting a highly selective pattern of cortical organization (White and Rock, 1981; White, 1989).

Most of the detailed physiological data available about neocortical synaptic responses were obtained in the in vitro slice preparation using local electrical stimulation paradigms that activate unidentified sets of axons (Thomson, 1986; Thomson et al., 1988; Sutor and Hablitz, 1989a; Nicoll et al., 1993). Recently, arduous

Received May 21, 1996; revised July 8, 1996; accepted July 22, 1996.

This work was supported by United States-Israel Binational Science Foundation Grant 91-00197 and Israel Science Foundation Grant 80/95-1. We thank B. W. Connors for helpful comments on this manuscript.

Correspondence should be addressed to Yael Amitai, Department of Physiology, Faculty of Health Sciences, P.O. Box 653, Ben-Gurion University, Beer-Sheva, Israel 84105.

Copyright (C) 1996 Society for Neuroscience $0270-6474 / 96 / 166567-12 \$ 05.00 / 0$ studies using dual impalements of cortical cells have started to elucidate the characteristics of excitatory synaptic connections between pairs of neighboring pyramidal cells (Mason et al., 1991; Thomson and West, 1993; Thomson and Deuchars, 1994). Unfortunately, the responses of cortical cells to thalamic afferents have been characterized mostly by extracellular single-unit studies in vivo. Technical difficulties hinder precise assessment of synaptic properties when intracellular recordings are performed in vivo (Ferster and Lindstrom, 1983; Douglas and Martin, 1991; Ferster and Jagadeesh, 1992; Steriade and Amzica, 1994; Steriade and Contreras, 1995). Virtually nothing is known about the comparative physiological properties of various synaptic inputs to a single cortical area or neuron.

Our goal in this study was to compare the effects of two separate input pathways onto single neocortical cells. The complex cellular organization of the neocortex makes this task especially difficult. Hence, our experiments were designed to take advantage of the unique morphological features of layer $\mathrm{V}$ cells: they are the biggest in the neocortex (Feldman, 1984), their horizontal axons travel for long distances in infragranular layers (Hallman et al., 1988; Chagnac-Amitai et al., 1990), and their apical dendrites span layers V to I. Most of the thalamocortical input to the cortex terminates in layer IV and thus is expected to impinge on the apical dendrites of layer V pyramidal cells (White, 1989). Thalamocortical axons also terminate in the vicinity of the layer V/VI border (Herkenham, 1980). The development of the thalamocortical slice preparation (Agmon and Connors, 1991, 1992) has made the thalamocortical synapse accessible to intracellular studies in vitro. We used this preparation to selectively 
activate thalamocortical fibers and horizontal intracortical axons, and assessed their synaptic properties in physiologically identified layer V neurons. Three main issues were examined: (1) the shape parameters of monosynaptic EPSPs from both tracts and their variance within and between neurons; (2) the temporal sequence and relative threshold of excitation and inhibition as it is recruited by each tract; and (3) a reexamination of the hypothesis that there is a specificity in the thalamocortical inputs onto physiologically defined types of neurons (Agmon and Connors, 1992).

\section{MATERIALS AND METHODS}

Slice preparation and maintenance. Thalamocortical slices were prepared as described previously (Gil and Amitai, 1996). Briefly, 52 male adult ( $>6$ weeks old) albino mice $(\mathrm{CD} / 1)$ were anesthetized with pentobarbital sodium, decapitated, and their brains were quickly immersed in ice-cold oxygenated artificial CSF (ACSF). ACSF composition was (in mM): 124.0 $\mathrm{NaCl}, 3.0 \mathrm{KCl}, 2.0 \mathrm{MgSO}_{4}, 1.25 \mathrm{NaHPO}_{4}, 2.0 \mathrm{CaCl}_{2}, 26.0 \mathrm{NaHCO}_{3}$, and 10.0 dextrose, and was saturated with $95 \% \mathrm{O}_{2} / 5 \% \mathrm{CO}_{2}, \mathrm{pH}$ 7.4. Thalamocortical slices, 400-450 $\mu \mathrm{m}$ thick, were cut on a Vibratome (Campdan Instruments, UK) in the precise angle described by Agmon and Connors (1991). The slices were kept in a holding chamber that contained ACSF at room temperature. After at least $1 \mathrm{hr}$ of incubation, a single slice was placed in a fluid-gas interface chamber thermostatically controlled to $35-36^{\circ} \mathrm{C}$. Oxygenated ACSF was perfused through the chamber at a rate of $5 \mathrm{ml} / \mathrm{min}$. The slices were illuminated from above and viewed with a dissecting microscope (Olympus SZ40), conditions that allowed an identification of layer IV (Chagnac-Amitai and Connors, 1989; Agmon and Connors, 1991). In some experiments, bicuculline methiodide (BMI; 10 $\mu \mathrm{M}$, Research Biochemicals, Natick, MA) or tetrodotoxin (TTX; $10 \mu \mathrm{M}$, Sigma, St. Louis, MO) was dissolved in ACSF and applied focally through a broken pipette to layer IV above the recording electrode.

Stimulation and recording. Extracellular and intracellular recording electrodes were pulled (Sutter Instrument, Novato, CA) from borosilicate, capillary glass tubing (World Precision Instruments, Sarasota, FL). Field potential electrodes (filled with $1 \mathrm{M} \mathrm{NaCl}, 6-8 \mathrm{M} \Omega$ ) were placed in layer IV. Thalamocortical or intracortical fibers were stimulated by 0.1 msec, 0.1-0.5 mA pulses delivered by two sets of bipolar microelectrodes made from sharpened tungsten wires. A horizontal cut was made with a fine needle between layers $\mathrm{V}$ and $\mathrm{IV}$, lateral to the recording area, to isolate infragranular horizontal connections. One stimulating electrode was placed in layer VI under the cut and at least $1 \mathrm{~mm}$ lateral to the recording area to activate these local corticocortical fibers while minimizing the activation of ascending thalamocortical fibers. The other stimulating electrode was placed at the lateral border of the ventrobasal nucleus of the thalamus. By moving the field potential electrode horizontally in layer IV, we located the area that generated the largest response (typical amplitude $0.1-0.5 \mathrm{mV}$, latency $<1 \mathrm{msec}$ from the stimulus) to thalamic stimulation, and cells were then recorded in layer $\mathrm{V}$ of the same vertical column. Intracellular micropipettes were filled with $4 \mathrm{M}$ potassium acetate (80-120 M, $\mathrm{pH} 7.2)$, and QX-314 (100 mM, Alomone, Jerusalem, Israel) was added to the filling solution in some experiments.

Recordings were made with an Axoclamp 2A amplifier (Axon Instruments, Foster City, CA). Hyperpolarizing current pulses (100 msec duration, $0.1-0.3 \mathrm{nA}$ amplitude, $0.3 \mathrm{~Hz}$ frequency) were injected through the electrode throughout the recording, and bridge balance was continually monitored. All cells reported here fulfilled the following criteria for stability: a resting potential more negative than $-65 \mathrm{mV}$ for at least 10 min, an input resistance higher than $25 \mathrm{M} \Omega$, and an action potential amplitude of at least $75 \mathrm{mV}$. The average input resistance of the cells was $45.5 \pm 20.5 \mathrm{M} \Omega$. Cells were characterized according to their temporal firing pattern during $0.8-1$-sec-long depolarizing current pulses. The recorded holding potentials were corrected according to the offset measured after withdrawal of the pipette from the cell.

Synaptic reversal potentials were estimated by evoking PSPs at different membrane potentials while injecting constant current through the electrode. When the PSP was clearly biphasic at one or more holding potentials, measurements were made at both amplitude peaks (Fig. 1A). IPSPs were identified by their relatively negative reversal potentials. Each PSP's onset was defined as the initial deflection point, and the latency of the responses was measured from the middle of the stimulus artifact (Fig. $1 B$ ). The stimulus intensity of the thalamic electrode was adjusted to evoke EPSPs of an amplitude close to $2.5 \mathrm{mV}$ at $-70 \mathrm{mV}$. If an inhibitory response was evident, the stimulus intensity was lowered to the minimal visible EPSP amplitude (around $0.15 \mathrm{mV}$ ) that could be distinguished through the noise (around $0.05 \mathrm{mV}$ ). To minimize differences arising from voltage-dependent currents, the intensity of the intracortical stimulation was adjusted to elicit an EPSP of an amplitude equal to the thalamic one at $-70 \mathrm{mV}$ holding potential. Cells that did not display any synaptic response to thalamic stimulation were not included in our analysis because there is no way to know whether the cell did not receive any thalamocortical synapses or whether its thalamic connections were severed by the slicing procedure.

Data were recorded on videocassette tapes, digitized off-line at $10 \mathrm{kHz}$, and analyzed semiautomatically with a software program written under visual $\mathrm{C}^{2+}$ (Labview, National Instruments). All PSPs were averaged from 15-20 sweeps, and the time profile of the variance, expressed as SD, was determined. Shape parameters were calculated for averaged EPSPs. The rate of rise was the slope of the line connecting the points at 10 and $90 \%$ of the peak amplitude. The membrane time constant was measured from the voltage decay after hyperpolarizing current pulse of $0.1 \mathrm{nA}$ by fitting a single exponential.

\section{RESULTS}

\section{Independence of evoked inputs}

Initially, we wanted to verify the location of the thalamocortical synapses we were activating and confirm that our stimulation paradigm was indeed evoking each input independently. The experimental arrangement is shown in Figure $2 A$. Synaptic responses in layer $\mathrm{V}$ cells were evoked separately by thalamic and intracortical stimulating electrodes. The cell displayed in Figure $2 B$ responded to thalamic pulses with a short-latency EPSP and a smaller, longer latency, possibly polysynaptic, EPSP. A drop of TTX $(10 \mu \mathrm{M})$ applied focally in layer IV, above the recording electrode, rapidly blocked the thalamocortical synaptic response in all cases $(n=5)$ without affecting the long-latency EPSP evoked from the thalamus or the intracortically evoked EPSP. Thus, we conclude that (1) under our experimental conditions, the physiologically significant thalamocortical input was contacting the apical dendrites of layer V cells within layer IV, and (2) our stimulation paradigm was evoking the two inputs independent of each other.

\section{Latency distribution of the PSPs}

Sixty-eight layer $\mathrm{V}$ cells exhibited synaptic responses to thalamic stimulation. Of these, the responses of 44 cells $(64.7 \%)$ had a smooth, unbroken shape, were depolarizing at all holding potentials, and had reversal potentials $\geq 0 \mathrm{mV}$ upon extrapolation. These were assumed to be pure EPSPs. Twenty (29.4\%) other cells exhibited a complex PSP that depolarization revealed to be a mixture of an EPSP and IPSP, and four cells (6.6\%) displayed pure IPSPs upon thalamic stimulation.

Figure $3 A$ is a histogram of the latencies of thalamocortical responses. Because thalamocortical synapses in the somatosensory cortex are all ultrastructurally asymmetric, and most probably excitatory (White, 1989), any IPSP evoked on cortical cells by thalamic stimulation must be at least disynaptic. The latencies to most (20 of 24) thalamic-evoked IPSPs in our experiments were between 1.8 and $2.6 \mathrm{msec}$. This agrees with previous measurements in this slice preparation (Agmon and Connors, 1992) and in vivo (Ferster and Lindstrom, 1983; Swadlow, 1995), and we suggest that this is the latency range of disynaptic responses. Only four cells exhibited IPSPs with latencies longer than $5 \mathrm{msec}$, and this probably represents polysynaptic (i.e., more than two synapses) activation. The latencies of the EPSPs evoked from the thalamus were mostly clustered in a narrow range, around $1 \mathrm{msec}$ $(0.6-1.4 \mathrm{msec})$, and this time interval is likely to represent monosynaptic activation. Only two EPSPs overlapped with the cluster of 

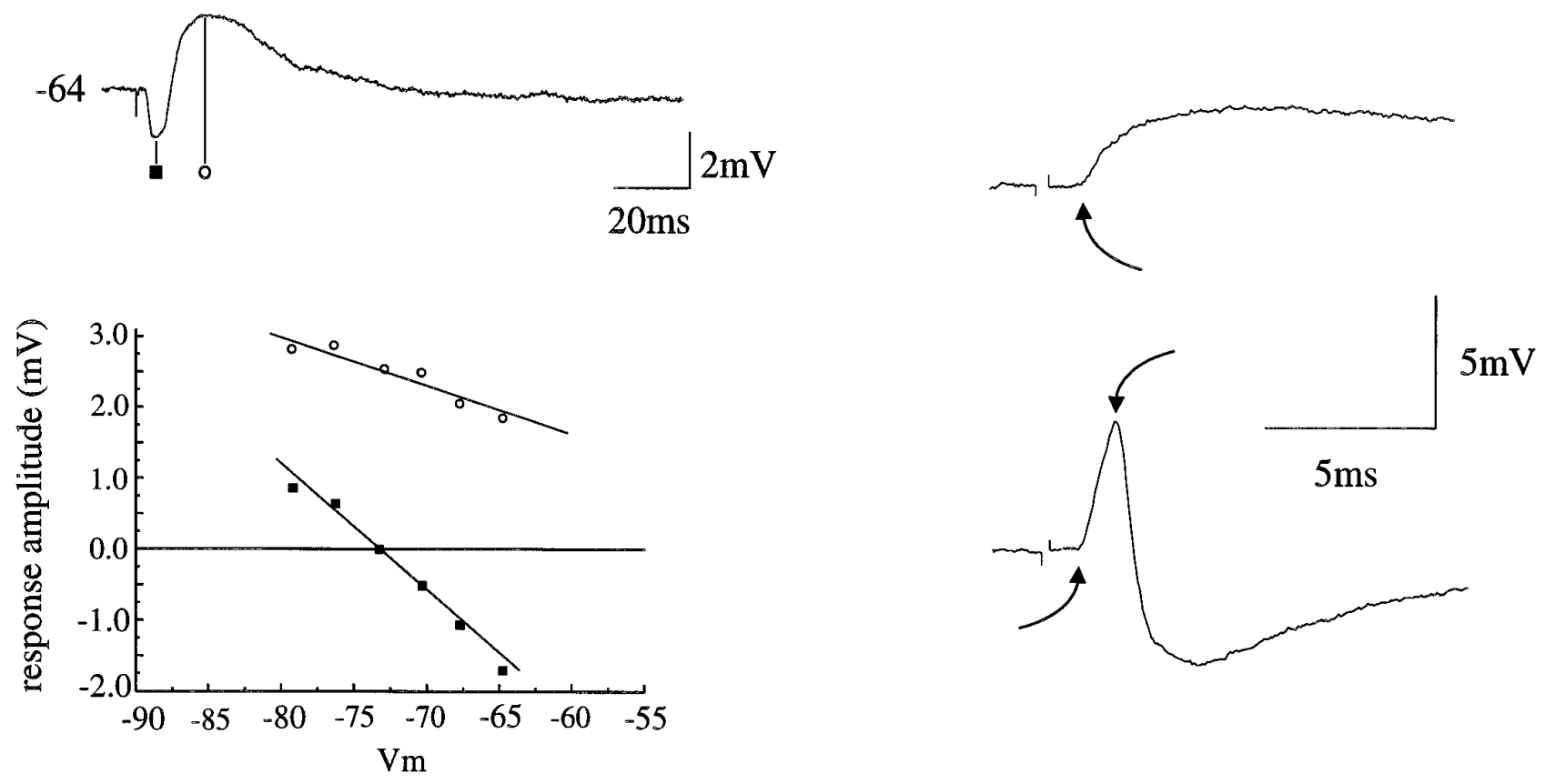

Figure 1. Representative synaptic responses to thalamic stimulation. $A$, PSPs were recorded at several membrane potentials, revealing biphasic response at $-64 \mathrm{mV}$ (top trace). The bottom panel plots the responses' peak amplitude against membrane potentials. The reversal potential of the negative peak $(\square)$ is $-73 \mathrm{mV}$, suggesting that it is a $\mathrm{GABA}_{\mathrm{A}}$-dependent IPSP. The reversal potential of the positive peak $(O)$ is estimated to be approximately -40 $\mathrm{mV}$ upon extrapolation, probably because of mixture of inhibitory and excitatory conductances. $B$, PSP onset was defined as the initial deflection point (curved arrows), and the latency of the responses was measured from the middle of the stimulus artifact. A cell displayed monophasic depolarizing response (top trace) to thalamic stimulation. Increasing slightly the stimulus intensity resulted in a biphasic synaptic response (bottom trace). The holding membrane potential was $-55 \mathrm{mV}$.

disynaptic IPSPs, and the rest of the EPSPs were scattered at latencies from 3 to $6 \mathrm{msec}$ and were regarded as polysynaptic.

Overall, we could elicit a synaptic response to intracortical lateral stimulation in 44 cells of the 68 cells that responded to thalamic stimulation. Like the thalamocortical responses, the minimal response time was $0.5 \mathrm{msec}$ and there was a clear peak in the latency distribution around $1 \mathrm{msec}$ (Fig. 3B). However, the latency distribution for intracortical PSPs had two main differences from the thalamocortical latency distribution. (1) There was no clear separation of a second latency cluster, but rather a continuous EPSP latency distribution up to 3 msec. (2) Only five cells (11.6\%) exhibited IPSPs at the intensities used in our paradigm, and these appeared $2.5 \mathrm{msec}$ and more after the stimulus, suggesting they were mostly polysynaptic. Thus, in no case was our intracortical stimulating electrode directly exciting interneurons that were innervating the recorded cells.

\section{Waveform fluctuations of PSPs}

In addition to the latency of the response, a uniform and consistent waveform serves as another criterion for monosynaptic transmission in complex neuronal circuits (Berry and Pentreath, 1976). We studied the shape fluctuations of the synaptic responses from both sources to explore whether EPSPs of short latency $(<1.8$ msec) were indeed less variable than responses of longer latencies, and whether response variance differed between the two synaptic tracts. Cells were held at membrane potentials of -70 $\mathrm{mV}$, and EPSPs were evoked at a fixed stimulus intensity and $0.5-1 \mathrm{~Hz}$ frequency. An average of 15-20 traces was obtained, and the SD time course (SDTC) of the EPSPs was plotted (Fig. 4). Indeed, for short latency-presumed monosynaptic responses (latency $<1.8 \mathrm{msec}$ ), the SDTC during the averaged EPSP did not differ greatly from baseline (Fig. $4 A$ ), reflecting the highly uniform shape and size of the EPSPs. The mean peak of the SDTC for presumed monosynaptic EPSPs was $0.12 \pm 0.05 \mathrm{mV}$, and none was larger than $0.3 \mathrm{mV}(n=81$ EPSPs). In contrast, EPSPs of longer latency $(>1.8 \mathrm{msec})$ had an SDTC that paralleled the shape of the EPSPs, and had a mean peak of $0.72 \pm 0.34 \mathrm{mV}$ (Fig. $4 B ; n=23$ EPSPs). This difference in variance between short- and long-latency EPSPs held even for responses within single cells, as illustrated in Figure $4 A$ : higher stimulus intensities recruited a long-latency EPSP that rode on the short-latency EPSP. The SDTC plot during the monosynaptic EPSP did not differ from baseline, but it increased sharply with the beginning of the longlatency EPSP. There was no difference between the SDTC of the thalamocortical and intracortical responses, however, implying that the synaptic order of the response, and not its pathway, determined the variability in shape. These data lend further support to the hypothesis that EPSPs of $0.6-1.8 \mathrm{msec}$ latency are monosynaptic.

\section{Thalamic input onto physiologically identified cells}

Intracellular recordings in rodent slices have demonstrated at least three distinct classes of neocortical neurons, characterized by their intrinsic firing properties. These classes are defined by the shapes of the individual action potentials and the temporal patterns of repetitive firing in response to injected current stimuli 
$\mathbf{A}$

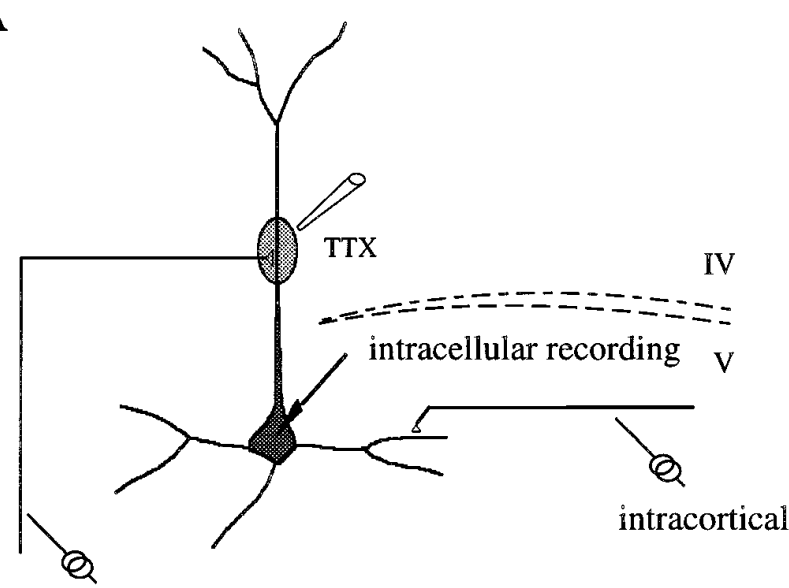

thalamocortical

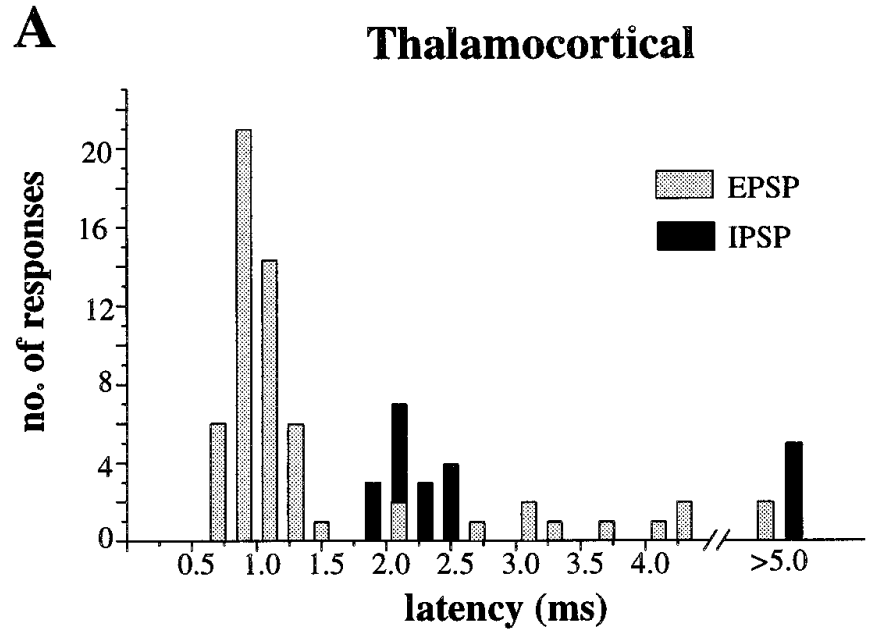

B

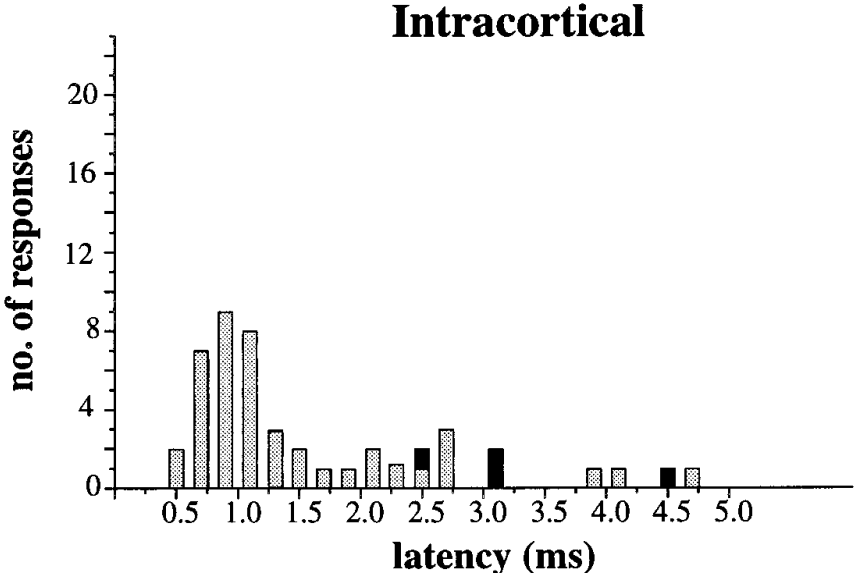

Figure 3. Synaptic latency histograms of EPSPs and IPSPs evoked by thalamocortical and intracortical stimulation. $A$, Latencies of synaptic responses of 68 cells to thalamic stimulation. Because disynaptic IPSPs had latencies between 1.8 and $2.6 \mathrm{msec}$, responses of latencies $<1.8 \mathrm{msec}$ are probably monosynaptic. $B$, The latencies of synaptic responses of 44 of the 68 cells in $A$ to intracortical stimulation. For both histograms, bins are $0.2 \mathrm{msec}$ wide. For example, the first bin of thalamocortical PSPs includes responses that had latencies $\geq 0.6 \mathrm{msec}$ and $<0.8 \mathrm{msec}$.

(Silva et al., 1991; Amitai, 1994). Fast-spiking (FS) cells had rapid action potentials (duration $<0.5 \mathrm{msec}$ ) with a relatively rapid rate of repolarization and a prominent afterhyperpolarization, and little or no frequency adaptation (Fig. $5 D$, asterisk; $n=3$ ).

Among pyramidal cells, some of these firing properties correlate with cell morphology (Chagnac-Amitai et al., 1990; Wang and McCormick, 1993; Kasper et al., 1994) (for review, see Amitai and Connors, 1994) or distinctive synaptic behavior (Chagnac-Amitai and Connors, 1989). A previous study in thalamocortical slices of mouse found a correlation between neurons' intrinsic firing properties and their probability of monosynaptic thalamocortical responses (Agmon and Connors, 1992). Most interestingly, IB cells tended not to receive direct thalamocortical EPSPs. However, two studies of carnivore neocortex in vivo concluded that all pyramidal cells, including IB cells, receive monosynaptic thalamocortical stimuli, IB cells often responded with alternating intervals of periodic bursting and single spiking with very little adaptation 


\section{Thalamocortical}

A

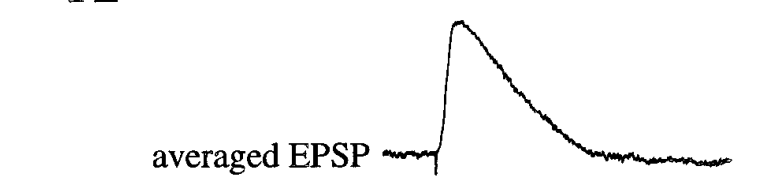

$<1.8 \mathrm{~ms}$

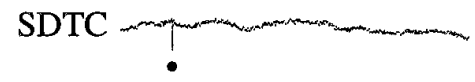

$1.3 \mathrm{~ms}$

B

\section{Intracortical}
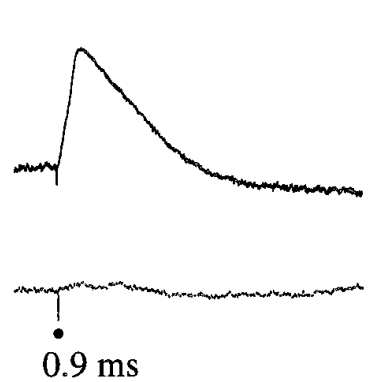

$0.9 \mathrm{~ms}$
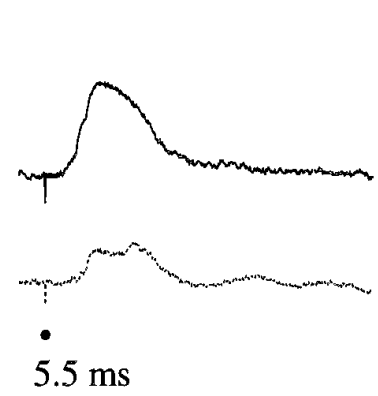

Intracortical (high intensity)

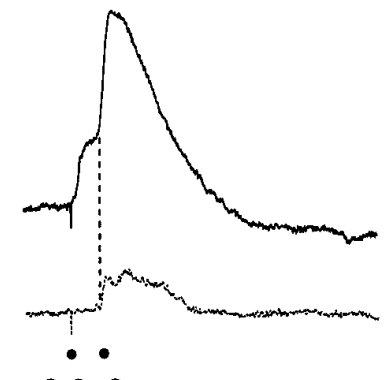

$0.9,8 \mathrm{~ms}$
$>1.8 \mathrm{~ms}$

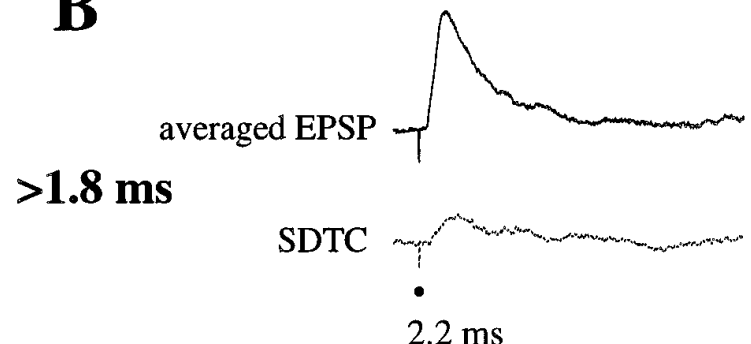

$2.2 \mathrm{~ms}$

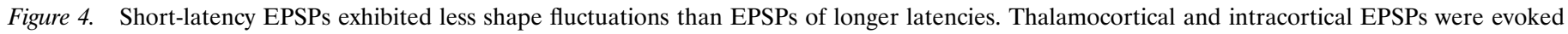

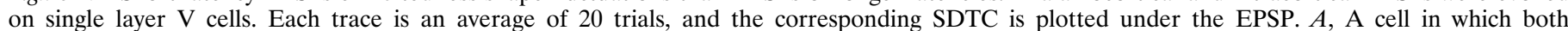

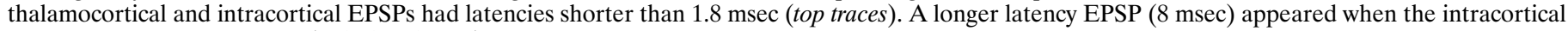

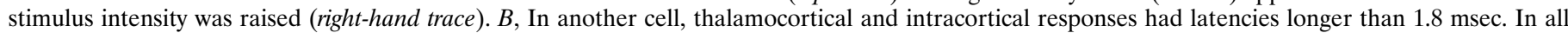

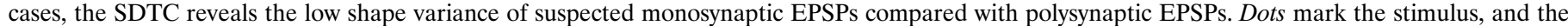
measured latencies of the responses are indicated.

input (Baranyi et al., 1993; Istvan and Zarzecki, 1994). We reexamined this issue here. Figure 5 illustrates examples of monosynaptic thalamocortical EPSPs evoked on cells of each firing type. The shapes of these EPSPs were highly variable across cells. In the case of the IB neuron, depolarizing the membrane to $-60 \mathrm{mV}$ allowed the EPSP to trigger a burst of action potentials similar to those evoked by a current pulse (Fig. 5C, inset). Figure 6 shows the thalamocortical PSPs' latency histogram reorganized by physiological cell type. It is evident that the latency distribution of thalamic inputs did not differ by cell type (Fig. 6); all cell types received monosynaptic input from the thalamus, and all pyramidal cells displayed disynaptic IPSPs. As expected, all cell types also received intracortical input (not shown). Because we had only three FS cells in our sample, we cannot address the possibility of GABAergic interneurons receiving feedforward inhibition after thalamocortical activation.

\section{Comparison of monosynaptic EPSPs waveform}

To compare the shape parameters of convergent monosynaptic EPSPs, we considered only those cases in which the amplitudes of both types of EPSPs on a single cell were closely matched, where no IPSP was evident, and where the SDTC remained flat throughout the EPSP, suggesting that there was no polysynaptic component (Fig. $7 A ; n=17$ ). Fifteen to twenty traces were averaged for each synaptic source. The average amplitude of the intracortical EPSPs was $2.64 \pm 0.81$, and the thalamocortical EPSPs averaged $2.63 \pm 0.70$, ranging from 1.7 to $3.7 \mathrm{mV}$ for both inputs. A plot of the averaged amplitudes of intracortical EPSPs versus thalamo- cortical EPSPs within the same cells is shown in Figure $7 B$, demonstrating a close match $(r=0.95)$.

Passive cable theory predicts that certain PSP shape parameters, such as the rate of rise of the EPSPs, and the relation between half-width and rise time, vary with the electrotonic distance between the synapse and the recording site (Rall, 1967). It has also been shown experimentally for hippocampal and neocortical pyramidal cells that distal inputs have longer half-widths and slower rise times than more proximal inputs (Turner, 1988; Nicoll et al., 1993). Anatomical data and our own experiments indicate that the two synaptic inputs tested here were contacting different parts of the cells' dendritic arbor. The thalamocortical input was most likely impinging on the apical or oblique dendritic branches within layer IV (Fig. 2), and the intracortical fibers were probably contacting the basal dendrites. Table 1 summarizes the EPSPs' shape indices for both inputs. All the grouped measurements for the two inputs were remarkably similar. Plotting the individual half-width against rise time discloses the wide range of each, with general overlapping of points from the two sets of inputs (Fig. $8 A$ ). The EPSPs' rate of rise also showed a high variability, ranging more than 10 -fold for both sets of inputs and displaying no correlation with the amplitudes (Fig. $8 B$ ). A plot of the rates of rise for intracortical EPSPs versus thalamocortical EPSPs in individual cells revealed a close correlation (Fig. $8 C$ ). This suggested to us that the dispersion of the shape parameters did not reflect major variations between the two sets of synapses, but rather was primarily determined by properties intrinsic to the 
A
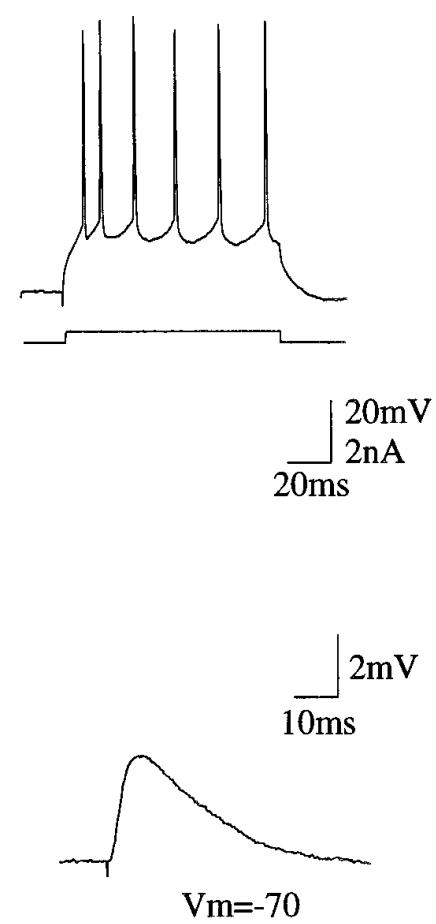

B
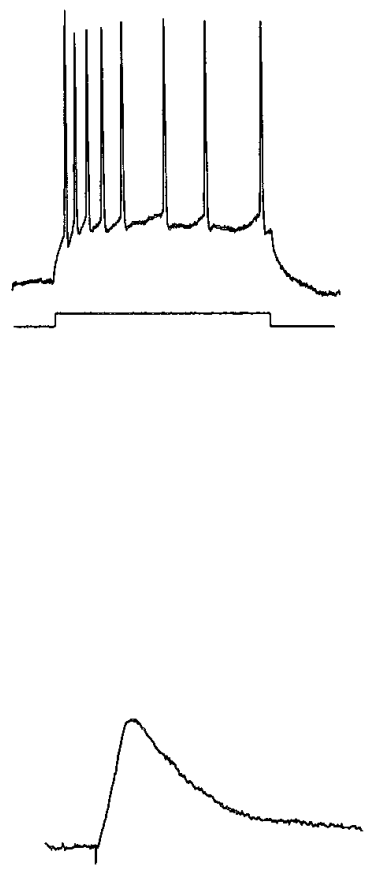

$\mathrm{C}$
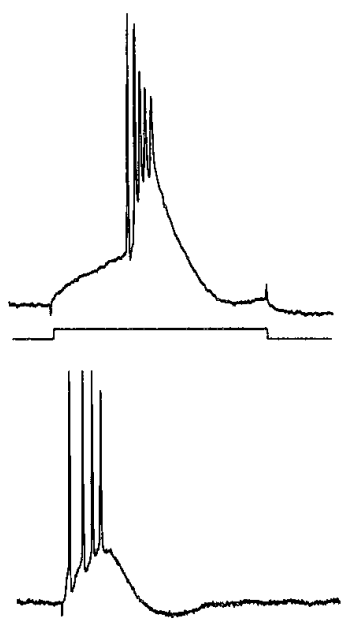

$\mathrm{Vm}=-60$

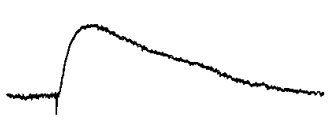

$\mathrm{D}$
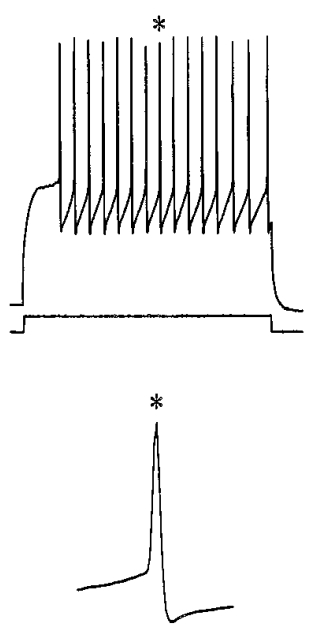

$1 \overline{\mathrm{ms}}$

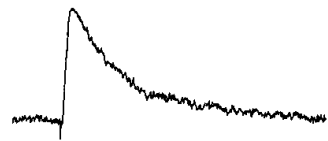

Figure 5. Thalamic-evoked EPSPs on four cells belonging to different physiological types. For each cell, the top trace is a representative spike train elicited by a current step, and the bottom traces display a monosynaptic EPSP of the same cell to thalamic stimulation at $-70 \mathrm{mV}$ membrane potential. $A, \mathrm{RS}_{1}$ cell. $B, \mathrm{RS}_{2}$ cell. $C$, IB cell. The inset shows a burst of action potentials in response to thalamic stimulation when the cell was depolarized to -60 $\mathrm{mV}$. D, FS cell. The inset displays a midtrain spike (asterisk) on an expanded time scale, showing typical fast rate of repolarization and deep afterhyperpolarization.

postsynaptic cell. A plot of the rate of rise versus the membrane time constant did not reveal any clear correlation (Fig. 8D). Clearly, when the EPSPs' rates of rise were normalized by the cells' time constants, the basic finding remained: when plotted against each other, the rates of rise for the two inputs were well correlated (Fig. $8 E ; r=0.93$ ). Because the firing properties of the cells are assumed to reflect active membrane properties, we also looked for correlation with the physiological classification of the cells. No difference is evident between IB and RS cells in the scatter of their EPSPs' rates of rise values (Fig. $8 E$ ). However, one FS cell in this group stood out, with close to double the taunormalized rate of rise compared with the fastest among the rest of the population (Fig. $8 E$ ). The two other FS cells we recorded exhibited only a thalamocortical input, but no intracortical EPSP, yet the normalized rate of rise for the thalamocortical EPSP was similarly high (Fig. 8E, arrows).

\section{Threshold for recruitment of inhibition}

Previous studies have found that the threshold for evoking an IPSP in neocortical slices is higher than for evoking an EPSP (Howe et al., 1987; Connors et al., 1988; Hirsch and Gilbert, 1991). Isolated IPSPs can be seen only when excitatory transmission is blocked (Benardo, 1994; Salin and Prince, 1996). On the other hand, it is generally sufficient to reduce the stimulus intensity to elicit EPSPs alone (Sutor and Hablitz, 1989a; Nicoll et al., 1993). In this study, we found a very different situation for the thalamocortical pathway: the latency histogram (Fig. 3) indicates that in 24 cells of $68(35 \%)$, the minimal stimulus intensity required to elicit a visible EPSP also elicited a clear IPSP along with it. In some cases, the threshold for evoking inhibition by thalamocortical activation was even lower than that of the thalamically evoked EPSPs; isolated IPSPs were observed in four cells, and in two of them, polysynaptic EPSPs were elicited only at higher stimulus intensities (Fig. $1 A$ ).

Figure $9 A$ shows a case in which the thalamically evoked EPSP and IPSP had equal thresholds. Repeated stimulation at a constant intensity evoked either an EPSP-IPSP sequence or, in $35 \%$ of the trials (18 of 50), failures of both responses together. Reducing the stimulus intensity increased the failure rate, but neither the EPSP nor the IPSP was ever evoked separately. The $1.2 \mathrm{msec}$ latency to the EPSP, along with its all-or-none character, suggested that it was generated monosynaptically by a single thalamocortical axon. The SDTC of successful events was essentially flat (Fig. 9B). This example demonstrates how tightly inhibition can be coupled to thalamic input. The modest shape and latency fluctuations imply a minimum neuronal circuit, such as the one schematized in Figure $9 C$ : a single thalamic axon contacts both the recorded pyramidal cell, generating a monosynaptic EPSP, and a GABAergic interneuron that innervates the same pyramidal cell. The interneuron fires reliably with each successful stimulation. Thus, either a single thalamic axon was sufficient to bring the interneuron above firing threshold, or additional thalamic axons converged on the interneuron, creating a subthresh- 


\section{EPSPs}

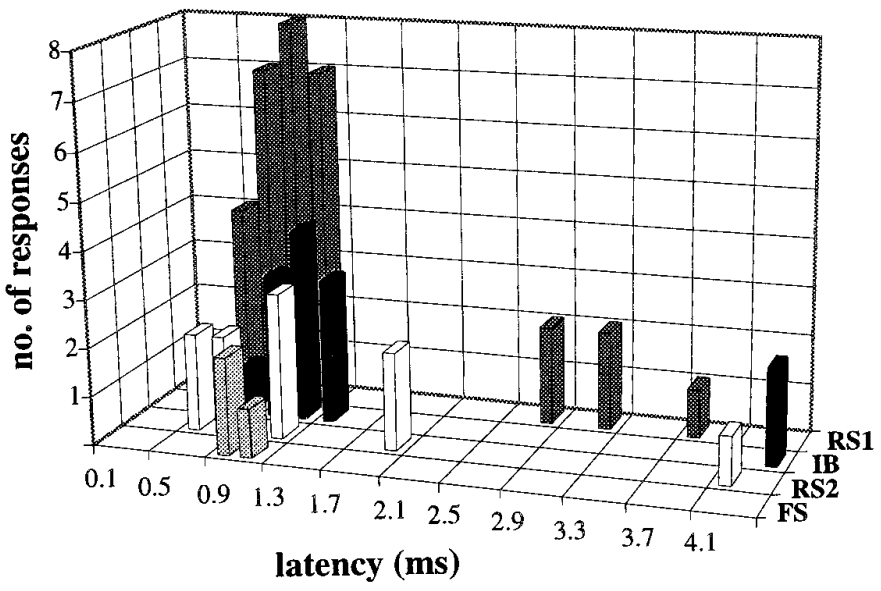

IPSPs

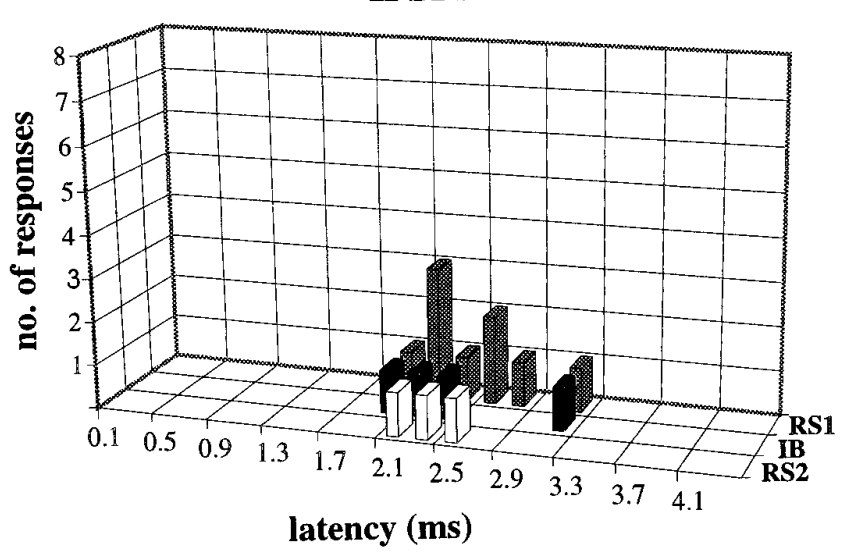

Figure 6. Latency distribution of thalamic-evoked EPSPs and IPSPs on different physiological cell types. Cells were classified according to their spike responses to a 0.8 - to 1-sec-long current pulse, as in Figure 5. Response bars are coded by cell types as indicated to the right of each row. Bins are $0.2 \mathrm{msec}$ wide. All neuronal types received monosynaptic thalamocortical EPSPs. All presumed pyramidal cell types exhibited disynaptic IPSPs upon thalamic stimulation (the only 3 FS cells in our sample did not).

old EPSP that reached spike threshold only with the activation of the specific axon.

In contrast to thalamocortical behavior, the appearance of intracortically evoked IPSPs depended strongly on the stimulus intensity. At the intensities required here to elicit an EPSP of an amplitude similar to the thalamocortical EPSPs, only 5 of the 44 cells $(11 \%)$ exhibited an IPSP (Fig. 3B). Figure 10 demonstrates the difference between the two pathways in their thresholds for recruitment of inhibition: the same cell was stimulated by each tract separately. The smallest visible response from the thalamus was an IPSP, and the minimal response from the cortex was an EPSP. As the stimulus intensity was increased gradually, the IPSP evoked from the thalamus increased monotonically in amplitude (Fig. 10A,B). The intracortical EPSP increased in amplitude at an intensity of 1.2 , but as the intensity was increased to 1.5, an IPSP appeared (Fig. 10 $A$, arrow). This IPSP entirely obscured the EPSP at an intensity of 2.0 (Fig. $10 A, B$ ). Figure $10 B$ summarizes these
A
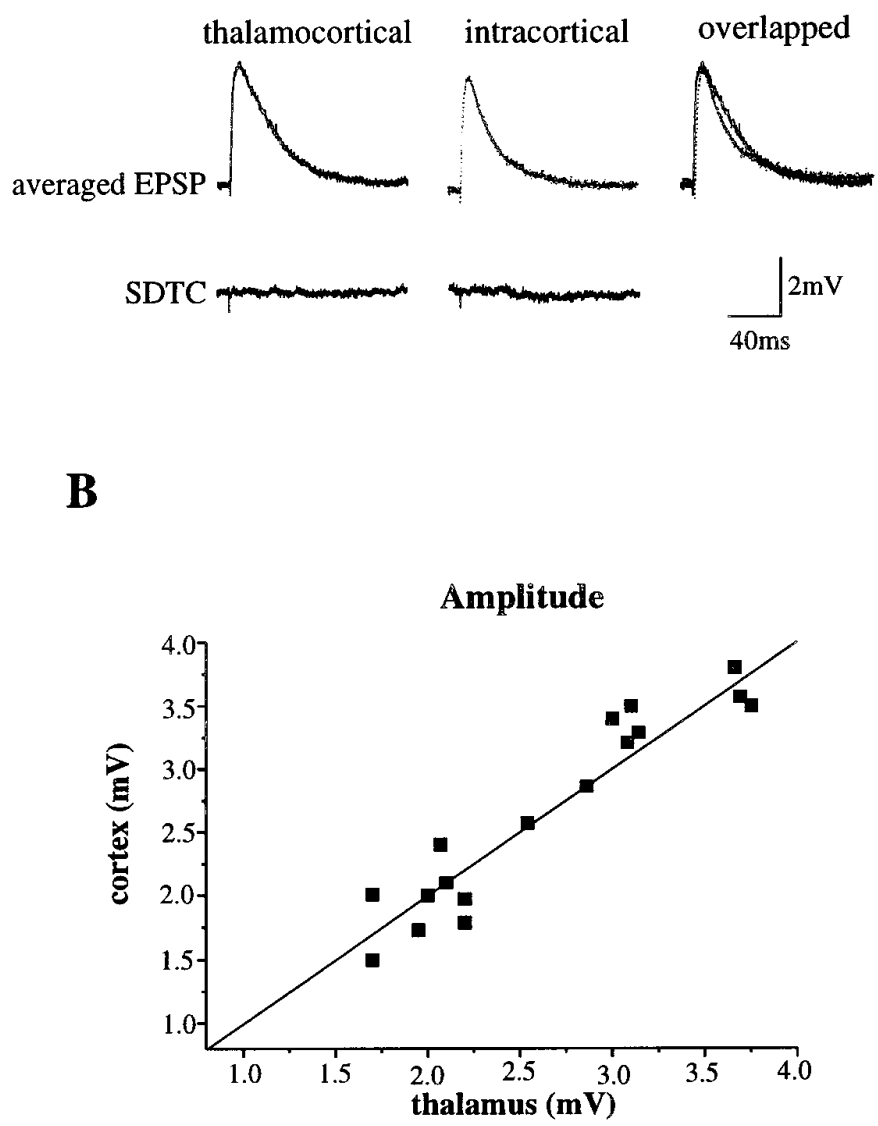

Figure 7. EPSPs from both sources on single cells were closely matched. Thalamocortical and intracortical monosynaptic EPSPs were evoked on single layer $\mathrm{V}$ cells. Close to equal amplitudes were achieved by adjusting the stimulus intensities. $A$, Representative EPSPs that were used for shape parameter analysis. Twenty traces were averaged for each synaptic source (top traces). The flat SDTC plots (bottom traces) suggest that there were no polysynaptic components. Overlapping the traces emphasizes the similarity in shape. $B$, Plot of the averaged amplitudes of intracortical EPSPs versus thalamocortical EPSPs. Each data point is a cell, and all points are tightly clustered along the line of equality $(r=0.95)$.

results. A focal application of the $\mathrm{GABA}_{\mathrm{A}}$ receptor antagonist BMI abolished both IPSPs, thalamocortical and intracortical (Fig. 10C).

Axons of layer $\mathrm{V}$ cells have been shown to project for long horizontal distances within more superficial laminae (Aroniadou and Keller, 1993). To rule out the possibility that the horizontal cut between layer $\mathrm{V}$ and IV was altering the circuit organization in a way that affected the thresholds for recruiting inhibition, we conducted similar experiments without cutting the slices. Ten cells were recorded. In three of them, an EPSP and an IPSP were evoked by thalamic stimulation at indistinguishable stimulus intensities. The intracortically evoked EPSPs were compounded by abundant polysynaptic activity, with no clear evidence for IPSPs (not shown).

The average reversal potential for all IPSPs evoked from the thalamus was $71.4 \pm 6.6 \mathrm{mV}(n=11)$, indicating that all were dependent on $\mathrm{GABA}_{\mathrm{A}}$-activated chloride conductances. We did not observe any late hyperpolarizing potentials that might correspond to $\mathrm{GABA}_{\mathrm{B}}$-dependent IPSPs in any of our recordings. 


\begin{tabular}{lcc}
\hline \multicolumn{3}{l}{ Table 1. Shape parameters of thalamocortical and intracortical EPSPs } \\
$\begin{array}{lcc}\text { EPSP } \\
\text { parameters }\end{array}$ & $\begin{array}{l}\text { Thalamocortical } \\
\text { input }\end{array}$ & $\begin{array}{l}\text { Intracortical } \\
\text { input }\end{array}$ \\
\hline $\begin{array}{l}\text { Amplitude }(\mathrm{mV}) \\
\text { Rise time }(10-90 \%)\end{array}$ & $2.63 \pm 0.70$ & $2.64 \pm 0.81$ \\
$\quad(\mathrm{msec})$ & $4.93 \pm 2.84$ & $4.86 \pm 2.21$ \\
Rate of rise (V/sec) & $1.02 \pm 0.80$ & $1.14 \pm 0.90$ \\
Half-width (msec) & $19.28 \pm 10.15$ & $17.84 \pm 8.26$ \\
Fall time $(10-90 \%)$ & $37.0 \pm 4.0$ & $36.0 \pm 5.0$ \\
$\quad(\mathrm{msec})$ & $0.09 \pm 0.05$ & $0.08 \pm 0.04$ \\
Rate of fall (V/sec) &
\end{tabular}

Thalamocortical and intracortical EPSPs were evoked on single layer V cells. Fifteen to twenty traces were averaged for each synaptic input. Data in the table are from those cells in which the amplitudes of both EPSPs were closely matched, no IPSPs were evident, and the SDTC remained flat throughout the course of the EPSP $(n=$ 17). All data are expressed as mean \pm SD.

\section{DISCUSSION}

This study directly compared the synaptic responses of two convergent pathways, thalamocortical and intracortical, on single neurons of neocortical layer V. The main conclusions are: (1) all neuronal types in layer $\mathrm{V}$ receive monosynaptic excitatory input from the thalamus; (2) EPSPs evoked by thalamocortical and intracortical pathways have very similar shape parameters within a given cell; and (3) these two pathways differ markedly in the degree to which they activate feedforward inhibition.

\section{Technical and methodological considerations}

We chose to study layer $\mathrm{V}$ neurons because their unique morphology enables separate and reliable activation of intracortical and thalamocortical fibers in vitro. Layer IV cells are generally considered the main recipients of thalamic input, but the activation of layer $\mathrm{V}$ cells by thalamocortical afferents should not be regarded as a minor feature of thalamocortical processing. A recent study showed that layer $V_{b}$ cells, together with layer IV cells, are the first in the barrel field to be activated by thalamic input (Armstrong-James et al., 1992). Thus, only layer V cells provide a fast and monosynaptically direct pathway from thalamic input to cortical output (Connors and Amitai, 1995).

A potential concern in this study is that thalamic stimulation may have antidromically activated axon collaterals of corticothalamic cells. However, there are several reasons why it is likely that our thalamic-evoked EPSPs were exclusively or primarily attributable to the orthodromic actions of thalamocortical fibers. First, the diameter of thalamocortical fibers is considerably larger than that of corticothalamic ones (Jones and Powell, 1969). Accordingly, corticothalamic axons have a relatively high threshold of

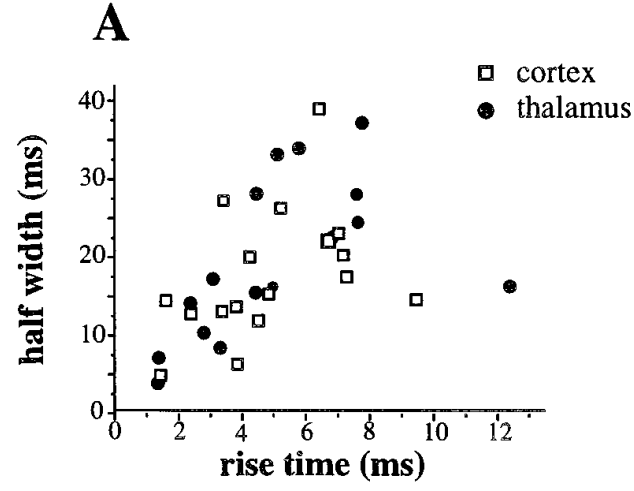

B

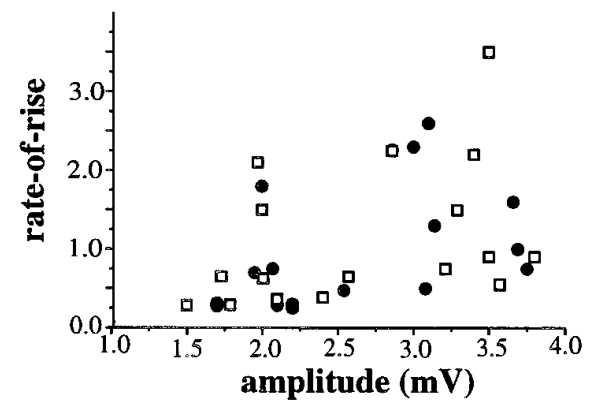

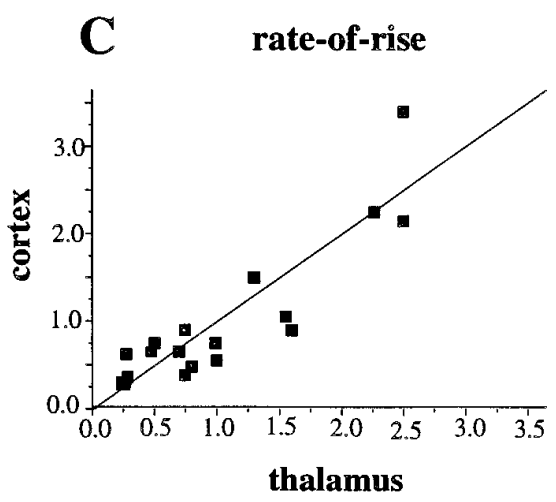

\section{D}

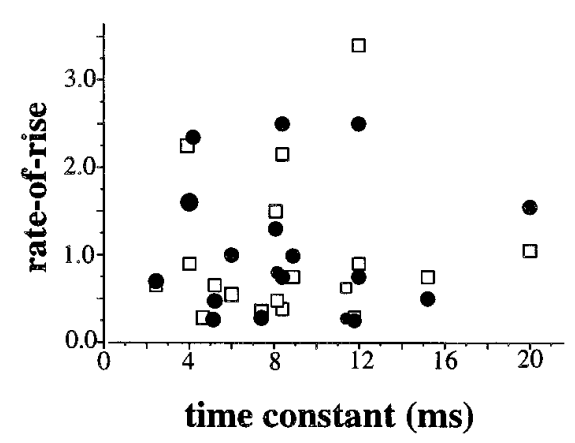

$\mathbf{E}$

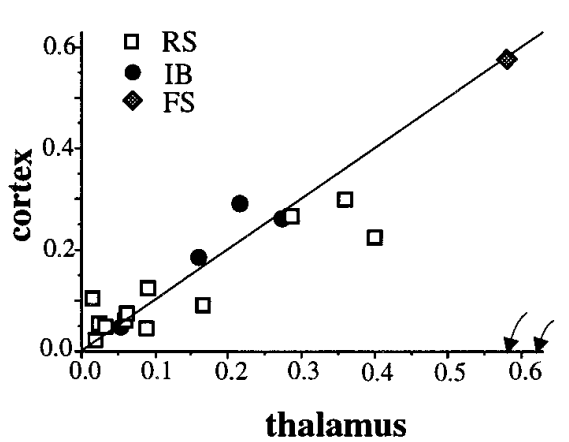

Figure 8. Comparison of the shape parameters of thalamocortical and intracortical EPSPs. $A$, Plot of the half-width versus rise time for intracortical ( $\square$ ) and thalamocortical (-) EPSPs, demonstrating wide and generally overlapping scatter for both input sets. $B$, Plot of the rates of rise versus amplitude for intracortical $(\square)$ and thalamocortical $(\bullet)$ EPSPs, showing similar scatter for both inputs and no clear correlation. $C$, Plot of the rates of rise for intracortical EPSPs versus thalamocortical EPSPs. Each data point represents a cell, and all data points are clustered along the line of equality $(r=0.93)$. $D$, Plot of the rate of rise versus membrane time constant $(\tau)$ for intracortical $(\square)$ and thalamocortical $(\bullet)$ EPSPs does not reveal any correlation. $E$, Plot of the EPSP rates of rise normalized by the membrane time constant $(\tau)$ for intracortical EPSPs versus thalamocortical EPSPs. The intrinsic firing properties of individual cells are indicated by different symbols. Data points are clustered along the line of equality. No difference is evident between the scatter of RS and IB cells, but note the outstandingly high value of normalized rate of rise of the FS cell's EPSP. The rates of rise of thalamocortical EPSPs in two additional FS cells are marked with arrows. 
A

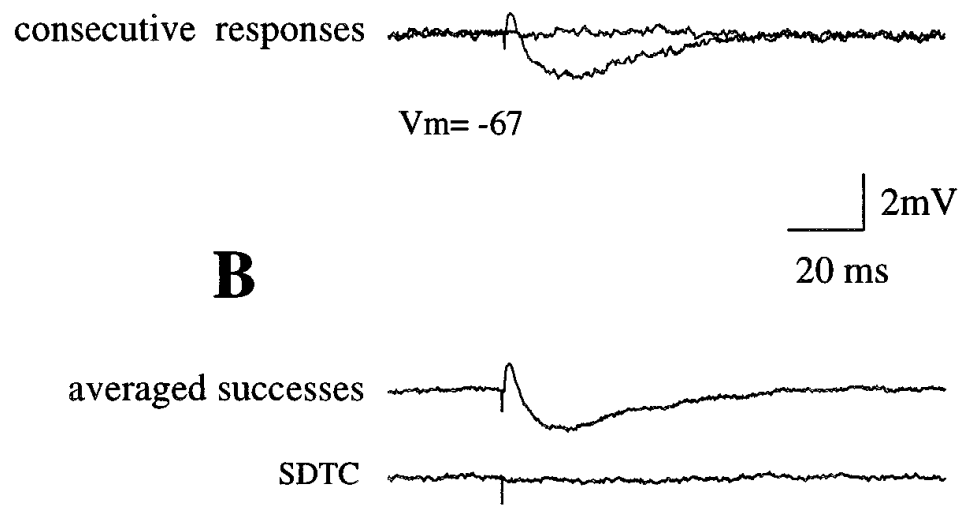

C

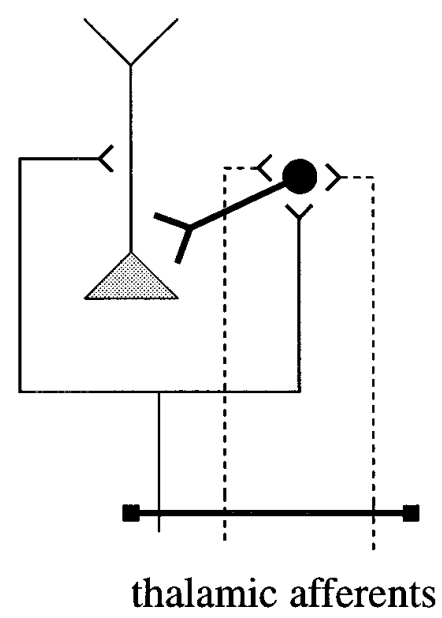

Figure 9. A cell exhibiting equal thresholds for thalamic-evoked monosynaptic EPSP and disynaptic IPSP. $A$, Single traces of consecutive responses to thalamic stimulation are overlapped, showing an EPSP-IPSP sequence and a failure of both responses. $B$, The top trace displays an average of 18 successful responses. The bottom trace plots the SDTC, demonstrating very little variance of shape of the complex response. $C$, Schematic diagram of a minimal neuronal circuit that can underlie the event illustrated in $A$ and $B$. A single thalamic axon innervates both the recorded pyramidal cell and an inhibitory neuron that innervates the same pyramidal cell. Possibly, additional thalamic axons converge on this interneuron, creating a subthreshold EPSP during events recorded as failures.

activation and a very slow conduction velocity (Ferster and Lindstrom, 1985; Swadlow, 1994). Second, corticothalamic cells are situated in layer VI. If these cells were activated antidromically, we would expect that the recruitment of inhibition would be similar to that evoked by stimulating layer VI. Yet, many studies used layer VI stimulation paradigms over the years (Connors et al., 1988; Chagnac-Amitai et al., 1990), and none has described IPSPs evoked in isolation from EPSPs. Thus, the reliable lowthreshold pattern of IPSP recruitment seems to be quite specific to the thalamocortical pathway. In addition, when corticothalamic cells were activated antidromically in vivo, inhibition was rarely evoked at all by this circuit (Ferster and Lindstrom, 1985).

\section{EPSPs}

We analyzed the shape parameters of thalamocortical and intracortical EPSPs in an attempt to infer differences in their properties or electrotonic location on cell dendrites. By design, EPSPs of equal amplitude were evoked from the two tracts. Most EPSPs were graded with stimulus intensity, and thus probably resulted from the summation of many unitary EPSPs generated by coactivated fibers. We have no way of estimating the number of fibers or synapses activated by each pathway. NMDA receptor-mediated currents contribute to EPSPs in the neocortex, and act to prolong their falling phase (Thomson, 1986; Jones and Baughman, 1988; Sutor and Hablitz, 1989b). Our previous results suggest that thalamocortical and intracortical synapses may differ in the relative contribution that NMDA receptors make to the evoked EPSPs (Gil and Amitai, 1996). Because NMDA receptors were not blocked in the present study, the rate of rise is more likely to reflect differences in electrotonic location than half-width or rate of fall. The fact that such difference was not found is, nevertheless, not surprising. Earlier studies using microstimulation along the apical dendrites of CA1 pyramidal cells found that proximaldistal differences in waveform are substantially smaller for large (1-5 mV), compared with small $(<1 \mathrm{mV})$, PSPs measured at the soma (Andersen et al., 1987; Turner, 1988). In a study of cultured cortical neurons, there was great overlap in the shape parameters of miniature EPSPs evoked on different parts of the dendritic tree (Bekkers and Stevens, 1996). Thus, one has to conclude that waveform analyses are not very reliable indicators of the electrotonic location of the EPSPs in cortical neurons. Our measurements suggest that synapses located on the midapical dendrite (i.e., thalamocortical) and synapses scattered on the basal dendritic tree (intracortical) produce very similar somatic effects. Active conductances in the dendrites of pyramidal cells (Amitai et al., 1993; Kim and Connors, 1993; Cauller and Connors, 1994; Stuart and Sakmann, 1994) are likely to alter EPSP size and waveforms.

An important finding of our study is the nearly exact match of the rates of rise of the two convergent sets of EPSPs within a given cell, despite wide variance across cells (Iriki et al., 1991). Similar data from neurons elsewhere in the CNS are scant. One recent study compared responses to single boutons stimulated at different dendritic locations in cultured hippocampal cells. The amplitudes of the synaptic events varied considerably from cell to cell, but were nearly the same for different boutons terminating on the same cell. Liu and Tsien (1995) found a correlation between EPSPs' size and the density of innervation on the postsynaptic cell, and speculated that the postsynaptic cell was controlling unitary synaptic strength. Our results also emphasize the importance of postsynaptic factors in determining the EPSP shape. The mechanism by which synaptic adjustments might occur postsynaptically is obscure. Our results show no correlation between EPSPs' rates of rise and membrane time constant, one indicator of a cell's passive electrotonic properties. However, the noticeably high normalized EPSPs' rates of rise of FS cells hints that the intrinsic cells' properties might be of significance.

Our observations of the similarity of EPSP kinetics do not exclude the possibility that there are tract-specific differences in 
A

\section{thalamocortical intracortical}

1
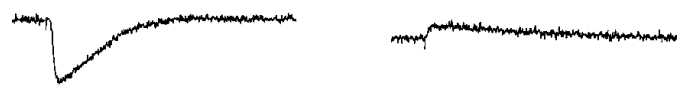

1.2
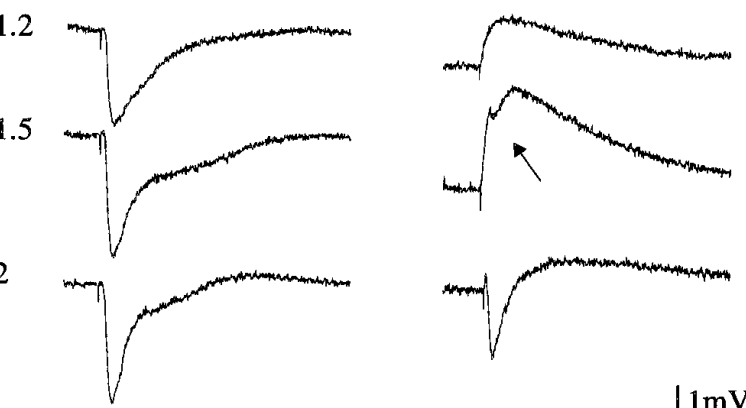

$\underset{25 \mathrm{~ms}}{1}$

B

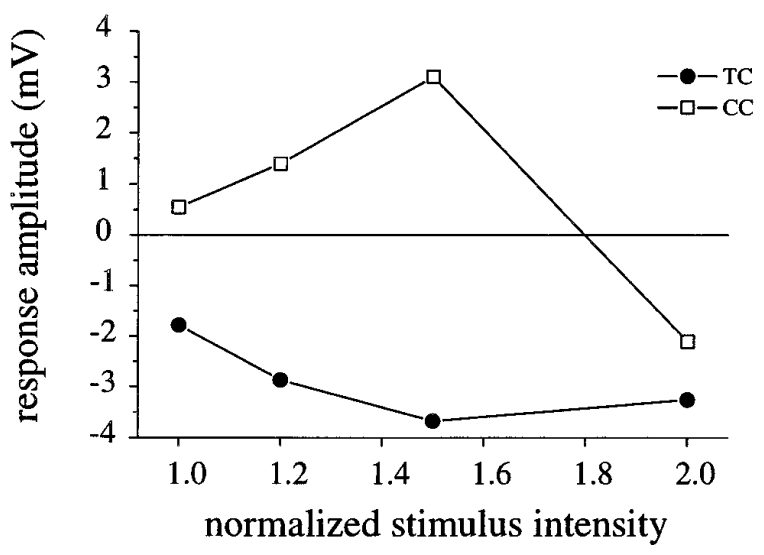

$\mathbf{C}$

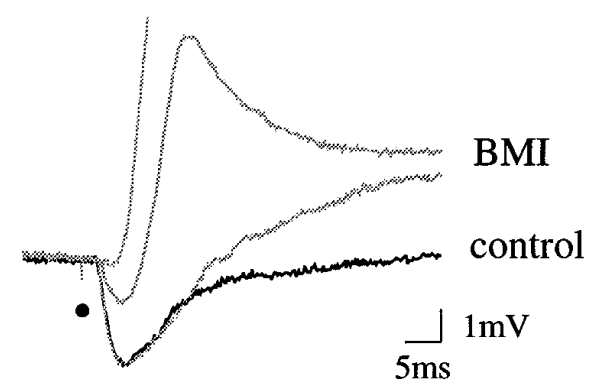

Figure 10. Thalamocortical and intracortical pathways differ in the relative threshold for activation of synaptic excitation and inhibition. $A$, Thalamocortical and intracortical synaptic responses evoked at four stimulus intensities on a single layer $\mathrm{V}$ cell. The cell was depolarized to $-62 \mathrm{mV}$. Stimulus intensities are normalized to the minimal intensity used for each pathway and marked at the left of the traces. The thalamocortical response was inhibitory at all intensities. The minimal intracortical response was excitatory, and IPSP appeared at an intensity of 1.5 (arrow). $B$, Summary diagram of the maximal amplitude of the synaptic responses from $A$, as a function of stimulus intensity. $C$, In the same cell, the thalamocortical IPSP was blocked by focal application of BMI $(10 \mu \mathrm{M})$ near the soma. The response under control conditions is displayed in black. The gray traces represent responses to stimuli at the same intensity, 30, 60, and $90 \mathrm{sec}$ after application of BMI. A dot indicates the stimulus. the more dynamic properties of synaptic function, such as frequency dependence and presynaptic modulation by transmitters (Gil et al., 1996).

\section{Differential recruitment of inhibition}

We found that the thalamocortical pathway had a strikingly lower threshold for the induction of feedforward inhibition than did the intracortical pathway. Previous intracellular studies, both in vivo (Ferster and Lindstrom, 1983) and in vitro (Agmon and Connors, 1992), also found that electrical stimulation of the appropriate thalamic nucleus evoked inhibitory potentials on a large portion of cortical pyramidal cells. Such strong and reliable inhibition requires that GABAergic interneurons be relatively easily excited by the thalamic input. Indeed, single-unit recordings in vivo have consistently demonstrated robust responses of suspected GABAergic neurons, identified by their fast spikes, to thalamocortical activation. These responses typically had very short latencies and low thresholds, were highly reliable, and had broad sensory receptive fields (Simons and Carvell, 1989; Swadlow, 1989, 1995; Welker et al., 1993).

The promptness and reliability of the thalamus-evoked inhibition was unmatched by intracortical activation. Distant placement of the stimulating electrode precluded the possibility that inhibitory interneurons were directly activated in the vicinity of the recorded pyramidal cell (Salin and Prince, 1996). All the intracortical IPSPs encountered had latencies consistent with di- or polysynaptic activation, and they appeared at a higher stimulus intensity than the monosynaptic EPSPs. Similarly, recruitment of inhibition was shown to be strongly correlated with the distance from the recorded cell and the stimulus intensity in a study of horizontal connections in superficial laminae of cat visual cortex (Hirsch and Gilbert, 1991).

Because each of the axonal tracts stimulated here was likely to innervate a different dendritic field in different laminae, they probably activated different sets of inhibitory cells. However, cortical GABAergic cells have been shown to have dendritic and axonal arbors that can span several layers (Fairen et al., 1984; Kisvarday et al., 1987). All fast-spiking cells (which are presumed to be inhibitory interneurons) impaled in our study within layer $\mathrm{V}$ received monosynaptic thalamic input, and in one of them we were able to evoke monosynaptic EPSPs via both stimulating electrodes.

Relevant anatomical information is fragmentary. Quantitative analysis at the electron microscopic level shows that the relative proportion of synapses terminating on pyramidal cells versus inhibitory cells is similar for both pathways. The vast majority $(80-90 \%)$ of excitatory corticocortical synapses in layer $\mathrm{V}$ is made with other pyramidal cells (Gabbott et al., 1987; Elhanany and White, 1990). Similarly, no $>20 \%$ of thalamocortical terminals contact inhibitory cells (White, 1989; DeFelipe and Farinas, 1992). Nevertheless, several studies by White and colleagues indicated that different classes of cortical cells receive characteristic proportion of synapses from the thalamus (for review, see White, 1989). For example, extreme differences were found between two types of nonspiny cells, occurring within the same thalamocortical projection field, in the numbers and percentages of the synapses they received by thalamic afferents (White and Rock, 1981). Our findings, together with the previous data cited above, indicate that the very low threshold for inhibitory recruitment by thalamic afferents is a generalized phenomenon of cortical organization, most likely involving specific innervation patterns onto cortical GABAergic cells. 
These data have important functional implications for neural information processing in the cortex. Because a relatively small number of thalamic relay cells diverge extensively to innervate a large number of cortical cells (Jensen and Killackey, 1987), each thalamic cell can impose widespread synchronized excitation. Strongly coupled inhibition could serve to prevent excessive excitatory drive while creating high temporal precision. It may also facilitate thalamocortical oscillations under certain behavioral states (Lytton and Sejnowski, 1991; Steriade and Contreras, 1995). Coupling between excitation and inhibition could also cause reduced expression of NMDA receptors in thalamocortical responses (Agmon and O'Dowd, 1992; Armstong-James et al., 1993; Gil and Amitai, 1996) and contribute to the loss of their susceptibility to long-term potentiation after the first week of life (Iriki et al., 1991; Crair and Malenka, 1995). In contrast, intracortical EPSPs are more weakly controlled by inhibition around threshold. Stronger IPSPs can be recruited, and they have the ability to nullify excitation, but only when activation is more synchronous, as when stimulus intensity increases. Corticocortical inputs are apt to be less synchronized because they arise from a multitude of other pyramidal cells in many cortical areas. Hence, these EPSPs are likely to readily express the late NMDA component, and be able to undergo plastic changes.

Finally, it has been shown recently that orientation tuning of cortical cells in the visual cortex is determined primarily by the thalamic input (Reid and Alonso, 1995; Ferster et al., 1996). Strong and brisk thalamocortical feedforward inhibition operating within a cortical column is bound to participate in shaping the spatial and temporal attributes of single neuron responses.

\section{REFERENCES}

Agmon A, Connors BW (1991) Thalamocortical responses of mouse somatosensory (barrel) cortex in vitro. Neuroscience 41:365-380.

Agmon A, Connors BW (1992) Correlation between intrinsic firing patterns and thalamocortical responses of mouse barrel cortex neurons. J Neurosci 12:319-330.

Agmon A, O'Dowd DK (1992) NMDA receptor-mediated currents are prominent in the thalamocortical synaptic response before maturation of inhibition. J Neurophysiol 68:345-349.

Amitai Y (1994) Membrane potential oscillations underlying firing patterns in neocortical neurons. Neuroscience 63:151-161.

Amitai Y, Connors BW (1994) Intrinsic physiology and morphology of single neurons in neocortex. In: Cerebral cortex, Vol 11, The barrel cortex of rodents (Jones EG, Diamond I, eds), pp 299-331, New York: Plenum.

Amitai Y, Friedman A, Connors B, Gutnick MJ (1993) Regenerative activity in apical dendrites of pyramidal cells in neocortex. Cereb Cortex 3:26-38.

Andersen P, Storm J, Wheal HV (1987) Thresholds of action potentials evoked by synapses on the dendrites of pyramidal cells in the rat hippocampus in vitro. J Physiol (Lond) 383:509-526.

Armstrong-James M, Fox K, Das-Gupta A (1992) Flow of excitation within rat barrel cortex on striking a single vibrissa. J Neurophysiol 68:1345-1358.

Armstrong-James M, Welker E, Callahan CA (1993) The contribution of NMDA and non-NMDA receptors to fast and slow transmission of sensory information in the rat S1 barrel cortex. J Neurosci 13:2149-2160.

Aroniadou VA, Keller A (1993) The patterns and synaptic properties of horizontal intracortical connections in the rat motor cortex. J Neurophysiol 70:1553-1569.

Baranyi A, Szente MB, Woody CD (1993) Electrophysiological characterization of different types of neurons recorded in vivo in the motor cortex of the cat. I. Patterns of firing activity and synaptic responses. J Neurophysiol 69:1850-1864.

Bekkers JM, Stevens CF (1996) Cable properties of cultured hippocampal neurons determined from sucrose-evoked miniature EPSCs. J Neurophysiol 75:1250-1255.
Benardo LS (1994) Separate activation of fast and slow inhibitory postsynaptic potentials in rat neocortex in vitro. J Physiol (Lond) 476.2:203-215.

Berry MS, Pentreath VW (1976) Criteria for distinguishing between monosynaptic and polysynaptic transmission. Brain Res 105:1-20.

Braitenberg V, Schüz S (1991) Anatomy of the cortex: statistics and geometry. Berlin: Springer.

Cauller LJ, Connors BW (1994) Synaptic physiology of horizontal afferents to layer 1 in slices of rat SI neocortex. J Neurosci 14:751-762.

Chagnac-Amitai Y, Connors BW (1989) Synchronized excitation and inhibition in neocortex sustained by burst-generating neurons. J Neurophysiol 62:1149-1162.

Chagnac-Amitai Y, Luhmann H, Prince DA (1990) Burst generating and regular spiking layer 5 pyramidal neurons of rat neocortex have different morphological features. J Comp Neurol 296:598-613.

Connors BW, Amitai Y (1995) Function of local circuits in neocortex: synchrony and laminae. In: The cortical neuron (Mody I, Gutnick MJ, eds), pp 123-140. New York: Oxford UP.

Connors BW, Malenka RC, Silva LR (1988) Two inhibitory postsynaptic potentials, and GABAa and GABAb receptor-mediated responses in neocortex of rat and cat. J Physiol (Lond) 406:443-468.

Crair MC, Malenka RCA (1995) Critical period for long-term potentiation at thalamocortical synapses. Nature 375:325-328.

Elhanany E, White EL (1990) Intrinsic circuitry: synapses involving the local axon collaterals of corticocortical projection neurons in the mouse primary somatosensory cortex. J Comp Neurol 291:43-54.

DeFelipe F, Farinas I (1992) The pyramidal neuron of the cerebral cortex: morphological and chemical characteristics of the synaptic inputs. Prog Neurobiol 39:563-607.

Douglas RJ, Martin KAC (1991) A functional microcircuit for cat visual cortex. J Physiol (Lond) 440:735-769.

Fairen A, DeFelipe J, Regidor J (1984) Nonpyramidal neurons: general account. In: The cerebral cortex, Vol 1, Cellular components of the cerebral cortex (Peters A, Jones EG, eds), pp 201-253. New York: Plenum.

Feldman M (1984) Morphology of the neocortical pyramidal neuron. In: Cerebral cortex, Vol 1, Cellular components of the cerebral cortex (Peters A, Jones EG, eds), pp 123-200. New York: Plenum.

Ferster D, Jagadeesh B (1992) EPSP-IPSP interactions in cat visual cortex studied with in vivo whole-cell patch recordings. J Neurosci 12:1262-1274.

Ferster D, Lindstrom S (1983) An intracellular analysis of geniculocortical connectivity in area 17 of the cat. J Physiol (Lond) 342:181-215.

Ferster D, Lindstrom S (1985) Synaptic excitation of neurons in area 17 of the cat neocortex by intracortical axon collaterals of corticogeniculate cells. J Physiol (Lond) 367:233-252.

Ferster D, Chung S, Wheat H (1996) Orientation selectivity of thalamic input to simple cells of cat visual cortex. Nature 380:249-252.

Gabbott PLA, Martin KAC, Whitteridge D (1987) Connections between pyramidal neurons in layer 5 of cat visual cortex (area 17). J Comp Neurol 259:364-381.

Gil Z, Amitai Y (1996) Adult thalamocortical transmission involves both NMDA and non-NMDA receptors. J Neurophysiol, in press.

Gil Z, Amitai Y, Castro-Alamacos MA, Connors BW (1996) Different frequency modulation and $\mathrm{GABA}_{\mathrm{B}}$ involvement at thalamocortical and intracortical synapses. Soc Neurosci Abstr, in press.

Hallman LE, Schofield BR, Lin CS (1988) Dendritic morphology and axon collaterals of corticotectal, corticopontine and callosal neurons in layer 5 of primary visual cortex of the hooded rat. J Comp Neurol 272:149-160.

Herkenham M (1980) Laminar organization of thalamic projections to the rat neocortex. Science 207:532-534.

Hirsch JA, Gilbert CD (1991) Synaptic physiology of horizontal connections in the cat's visual cortex. J Neurosci 11:1800-1809.

Howe JR, Sutor B, Zieglgansberger W (1987) Baclofen reduces postsynaptic potentials of rat neocortical neurons by an action other than its hyperpolarizing action. J Physiol (Lond) 384:539-569.

Iriki A, Pavlides C, Keller A, Asanuma H (1991) Long-term potentiation of thalamic input to the motor cortex induced by coactivation of thalamocortical and corticocortical afferents. J Neurophysiol 65:1435-1441.

Istvan PJ, Zarzecki P (1994) Intrinsic discharges patterns and somatosensory inputs for neurons in Raccoon primary somatosensory cortex. J Neurophysiol 72:2827-2839. 
Jensen KF, Killackey HP (1987) Terminal arbors of axons projecting to the somatosensory cortex of the adult rat. I. The normal morphology of specific thalamocortical afferents. J Neurosci 7:3529-3543.

Jones KA, Baughman RW (1988) Both NMDA and non-NMDA subtypes of glutamate receptors are concentrated at synapses on cerebral cortical neurons in culture. Neuron 7:593-603.

Jones EG, Powell TPS (1969) An electron microscopic study of the mode of termination of cortico-thalamic fibers within the sensory relay nuclei of the thalamus. Proc R Soc Lond [Biol] 172:173-185.

Kasper E, Larkman AU, Lübke J, Blakemore C (1994) Pyramidal neurons in layer 5 of the rat visual cortex. I. Correlation between cell morphology, intrinsic electrophysiological properties and axon targets. J Comp Neurol 339:459-474.

Kim HG, Connors B (1993) Apical dendrites of the neocortex: correlation between sodium- and calcium-dependent spiking and pyramidal cell morphology. J Neurosci 13:5301-5311.

Kisvarday ZF, Martin KAC, Friedlander MJ, Somogyi P (1987) Evidence for interlaminar inhibitory circuits in the striate cortex of the cat. J Comp Neurol 260:1-19.

Liu G, Tsien RW (1995) Properties of synaptic transmission at single hippocampal synaptic boutons. Nature 375:404-408.

Lytton WW, Sejnowski TJ (1991) Simulations of cortical pyramidal neurons synchronized by inhibitory interneurons. J Neurophysiol 66: 1059-1079.

Mason A, Nicoll A, Stratford K (1991) Synaptic transmission between individual pyramidal neurons of the rat visual cortex in vitro. J Neurosci 11:72-84.

McCormick DA, Connors B, Lighthall JW, Prince DA (1985) Comparative electrophysiology of pyramidal and sparsely spiny stellate neurons of the neocortex. J Neurophysiol 54:782-806.

Nicoll A, Larkman A, Blackmore C (1993) Modulation of EPSPs shape and efficacy by intrinsic membrane conductances in rat neocortical neurons in vitro. J Physiol (Lond) 468:693-710.

Rall W (1967) Distinguishing theoretical synaptic potentials computed for different soma-dendritic distribution of synaptic inputs. J Neurophysiol 30:1138-1168.

Reid CR, Alonso J-M (1995) Specificity of monosynaptic connections from thalamus to visual cortex. Nature 378:281-284.

Salin PA, Prince DA (1996) Electrophysiological mapping of GABA receptor-mediated inhibition in adult rat somatosensory cortex. J Neurophysiol 75:1589-1600.

Silva LR, Amitai Y, Connors B (1991) Intrinsic oscillations of neocortex generated by layer 5 pyramidal neurons. Science 251:432-435.

Simons DJ, Carvell GE (1989) Thalamocortical response transformation in the rat vibrissa/barrel system. J Neurophysiol 61:311-330.

Steriade M, Amzica F (1994) Dynamic coupling among neocortical neurons during evoked and spontaneous spike-wave seizure activity. J Neurophysiol 72:2051-2069.
Steriade M, Contreras D (1995) Relations between cortical and thalamic cellular events during transition from sleep patterns to paroxysmal activity. J Neurosci 15:623-642.

Stuart G, Sakmann B (1994) Active propagation of sodium action potentials into neocortical pyramidal cell dendrites. Nature 367:67-72.

Sutor B, Hablitz JJ (1989a) Excitatory post synaptic potentials in rat neocortical neurons in vitro. I. Electrophysiological evidence for two distinct EPSPs. J Neurophysiol 61:607-620.

Sutor B, Hablitz JJ (1989b) EPSPs in rat neocortical neurons in vitro. II. Involvement of $N$-methyl-D-aspartate receptors in the generation of EPSPs. J Neurophysiol 61:621-634.

Swadlow HA (1989) Efferent neurons and suspected interneurons in S-1 vibrissa cortex of the awake rabbit: receptive fields and axonal properties. J Neurophysiol 62:288-308.

Swadlow HA (1994) Efferent neurons and suspected interneurons in motor cortex of the awake rabbit: axonal properties, sensory receptive fields, and subthreshold synaptic inputs. J Neurophysiol 71:437-453.

Swadlow HA (1995) Influence of VPM afferents on putative inhibitory interneurons in $\mathrm{S} 1$ of the awake rabbit: evidence from cross correlation, microstimulation, and latencies to peripheral sensory stimulation. J Neurophysiol 73:1584-1599.

Thomson AM (1986) A magnesium-sensitive post-synaptic potential in rat cerebral cortex resembles neuronal responses to $N$-methylaspartate. J Physiol (Lond) 370:531-549.

Thomson AM, Deuchars J (1994) Temporal and spatial properties of local circuits in neocortex. Trends Neurosci 17:119-126.

Thomson AM, West DC (1993) Fluctuations in pyramid-pyramid excitatory postsynaptic potentials modified by presynaptic firing pattern and postsynaptic membrane potential using paired intracellular recordings in rat neocortex. Neuroscience 54:329-346.

Thomson AM, Girdlestone D, West DC (1988) Voltage-dependent currents prolong single-axon postsynaptic potentials in layer III pyramidal neurons in rat neocortical slices. J Neurophysiol 60:1896-1907.

Turner DA (1988) Waveform and amplitude characteristics of evoked responses to dendritic stimulation of CA1 guinea-pig pyramidal cells. J Physiol (Lond) 395:419-439.

Wang Z, McCormick DA (1993) Control of firing mode of corticotectal and corticopontine layer $\mathrm{V}$ burst-generating neurons by norepinephrine, acetylcholine, and 1S,3R-ACPD. J Neurosci 13:2199-2216.

Welker E, Armstrong-James M, Van der Loos H, Kraftsik R (1993) The mode of activation of a barrel column: response properties of single units in the somatosensory cortex of the mouse upon whisker stimulation. Eur J Neurosci 5:691-712.

White EL (1989) Cortical circuits: synaptic organization of the cerebral cortex, structure, function and theory. Boston: Birkhauser.

White EL, Rock MP (1981) A comparison of thalamocortical and other synaptic inputs to dendrites of two non-spiny neurons in a single barrel of mouse SmI cortex. J Comp Neurol 195:265-277. 